аспирант кафедры теории и истории государства и права

Северо-Кавказского федерального университета, адвокат адвокатской палаты Ставропольского края

\section{«МЯГКОЕ ПРАВО» КАК РЕГУЛИРУЮЩИЙ ИНСТРУМЕНТ МЕЖДУ ПРАВОМ И ПОЛИТИКОЙ}

\section{Аннотация:}

В статье рассматривается проблема трактовки так называемого "мягкого права» в контексте структурно-функционального анализа как одного из основных приемов исследования политико-правовых явлений. Оценка существующих подходов к трактовке изучаемого феномена как в отечественной правовой литературе, так и в зарубежной показывает, что в тех случаях, когда «мягкое право» признается самостоятельным политико-правовым явлением, его в действительности определяют в контексте функционального подхода, абстрагируясь от структурного анализа, так как последний приводит к очевидному конфликту с понятиями права вообще и средств правового регулирования. Исследование основано на использовании обще- и частнонаучных методов, а также структурного и функционального анализа политико-правовых явлений. В статье сформулированы выводы, что наиболее конструктивным приемом оценивания «мягкого права» как политико-правовой категории служит функциональный подход.

\section{Ключевые слова:}

«мягкое право», право, функциональный порядок, структура, целостность права, мягкое регулиро вание, правовая система, обязательность права.
PhD student, Theory and History of State and Law Department, North Caucasus Federal University, Lawyer, Law Chamber of the Stavropol Territory

\section{SOFT LAW AS A REGULATORY TOOL BETWEEN LAW AND POLICY}

\begin{abstract}
Summary:
The paper deals with the problem of interpreting the soft law in the context of structural and functional analysis as one of the main research methods of political and legal phenomena. The author reviews the existing approaches to interpreting the soft law in domestic and international legal literature. The analysis demonstrates that if the soft law is recognized as an independent political and legal phenomenon, in fact, it is reviewed in the context of the functional approach avoiding the structural analysis, since the latter leads to an obvious conflict with the concepts of law at large and the means of legal regulation. The research is based on the general and special scientific methods as well as the structural and functional analysis of political and legal phenomena. It is concluded that a functional approach is the most useful and helpful technique for analyzing the soft law as a political and legal category.
\end{abstract}

Keywords: soft law, law, functional order, structure, integrity of law, soft regulation, legal system, mandatory of law.

В современной правовой литературе одной из наиболее популярных и актуальных тем является феномен так называемого «мягкого права». Исследования в данном направлении ведутся с самых разных позиций по отношению к этому виду права: как регулирующего инструмента в области международного права [1], способа эффективного управления в сфере корпоративного, банковского права [2], средства восполнения пробелов и разрешения коллизий в международном праве [3], инструмента эффективной современной политики и т. п. При этом не менее четко в специальной литературе прослеживается тенденция, состоящая в отказе признавать «мягкое право» типом права или неким самостоятельным правовым феноменом, средства «мягкого права» в лучшем случае сводятся к способам и средствам решения политических задач, набору необязательных правил поведения и т. д., которые являются чем угодно, но не обладают свойствами и признаками права.

В действительности, в обсуждении проблематики «мягкого права» как в отечественной правовой литературе, так и в зарубежной не сложилось сколько-нибудь устойчивого понимания данного феномена. Зачастую речь идет не столько о трактовке понятия и определении его сущностных признаков, сколько о констатации ряда случаев политико-правовой практики, в которых с помощью рекомендательных инструментов были достигнуты результаты, типичные для использования традиционных правовых средств и способов регулирования. В связи с этим проявляются две очевидные тенденции. С одной стороны, «эффективность» или «функциональность» способствуют повышению интереса к практике применения механизмов решения политико-правовых задач, которые предлагаются гибкими средствами «мягкого» воздействия. С другой стороны, поскольку эти средства и способы направлены на решение традиционно политико-правовых задач, постольку возникает их соответствующая характеристика как права или типа права.

Несмотря на распространенность литературы по тем или иным аспектам «мягкого права», по-прежнему во многом не решенными остаются вопросы о том, можно ли его считать самостоя- 
тельным явлением политико-правовой сферы, в какой мере его следует рассматривать последовательно как аналитическую категорию, каков его онтологический статус, какие теоретические и методологические приемы адекватны для изучения и объяснения данного феномена? В подавляющем большинстве публикаций о проблеме «мягкого права» отнюдь не предлагается ясная и непротиворечивая дефиниция соответствующего понятия. Как правило, исследователи пишут не о сущности и отличительных признаках «мягкого права», а лишь об «использовании», точнее о некоторых конкретных случаях его применения, показывая фрактологическую грань вопроса. Иными словами, на передний план выдвигается не то, что «мягкое право» является собственно правом, этот момент подразумевается, а то, что необеспеченные никакими обязательными, гарантирующими исполнение, традиционными юридическими механизмами и средствами положения, выраженные в той или иной форме, фрактически решают те задачи политико-правовой сферы, которые обычно решаются строго юридическими средствами.

В силу того что средства «мягкого права» не требуют специального, строго юридического обеспечения соответствующих положений и норм, не грозя при этом адресатам таких положений никакими санкциями и мерами ответственности, даже исключая как таковую предпосылку обязательности нормы и ее действия, они становятся популярным способом и формой «встраивания» политических и правовых акторов в злободневные и актуальные социальные процессы, которые чрезвычайно интенсивно развиваются в условиях интенсификации и ускорения обмена информацией, научно-технического прогресса в целом. Для уровней законодателя и межгосударственного общения такой подход упрощает поиск адекватных и обоснованных правовых средств, поскольку позволяет сорормулировать лишь некий общий механизм, контуры для выработки будущих, возможно, обязательных решений для конкретных вызовов и проблем.

При всем разнообразии подходов к трактовке «мягкого права» центральным признаком, который легко прослеживается в попытках определить сущностное значение и соответствующее понятие, является функциональность регулирующих поведение инструментов. Иными словами, при анализе «мягкого права» на передний план выходит идея функции, рассматриваемой как первичная по отношению к структуре. По сути это классическая тема социологии, особенно в интерпретации Н. Лумана [4], Т. Парсонса [5] и др. Для функциональной теории, в частности Н. Лумана, характерно признание первичности функции относительно структуры. Общество интерпретируется как некий функциональный порядок. Для функциональной концепции Н. Лумана было критическим расхождение с теориями причинности, которые, по его мнению, ограничивали понимание общества и социальной жизни как функционального порядка. В связи с этим категория фрункции отграничивается от понятий причины и цели, задающих конечность развития и функции. По мнению Н. Лумана, функциональность является бесконечной: «Всякое каузальное определение включает в себя в самых различных направлениях ссылки на бесконечное: каждое следствие имеет бесконечно много причин, каждая причина имеет бесконечно многие следствия» [6, S. 16]. «Функция, - писал исследователь, - это не отдельный вид каузального отношения, а каузальное отношение является частным случаем применения функционального порядка» [7, S. 16].

В контексте функциональной теории Н. Лумана «мягкое право» предстает как одно из частных проявлений функционального порядка. Оно становится некой специальной, обособленной правовой функцией, выполняя те же или аналогичные задачи, которые в условиях социального порядка реализует право с его набором традиционных политико-правовых инструментов. В контексте функциональности (абстрагированной от закона причинности и цели, как в теории Н. Лумана) «мягкое право» - тоже право, поскольку очевидно, что результаты его функционирования совпадают с результатами действия права. При этом важны не столько прочность и стабильность достигнутых итогов, традиционно связываемые с действием права, сколько фрактические результаты. «Мягкое право» как категория, интерпретируемая в контексте фрункциональной теории Н. Лумана, выступает одним из множества проявлений функции права в социальном порядке. Те сфреры жизни и задачи, которые не охватываются традиционными правовыми средствами в силу разнообразных причин, возделываются средствами «мягкого права». Результаты, достигнутые при использовании «мягкоправовых средств» регулирования, еще больше укрепляют позиции «мягкого права», приводя к чисто функциональному его пониманию как типа права.

Если мы вводим категорию «структура» в анализ «мягкого права», то, очевидно, последнее сразу вступает в конфрликт с понятием права вообще. Не ставя целью установление структуры «мягкого права», некоторые исследователи легко пренебрегают важностью структурного анализа как одного из ключевых подходов к изучению правовых феноменов. Известный российский правовед Д.А. Керимов указывал на «необходимость различать внутреннюю и внешнюю структуру правовых явлений» [8, с. 199]. По его мнению, «внутреннюю структуру составляет определенная связь частей единого целостного правового образования, а внешнюю - определенная связь целостного правового образования с другими правовыми явлениями» [9]. Отсюда возникает несколько существенных соображений относительно разъяснения природы и характера понятия «мягкое право». 
Во-первых, с точки зрения структуры «мягкое право», соответственно, может рассматриваться как феномен, обладающий или не обладающий свойством целостности, если оно претендует быть самостоятельным явлением, неким типом права. В действительности так называемое «мягкое право» этого свойства не имеет, поскольку содержит, по признанию подавляющего большинства исследователей, крайне разнообразные явления: от необязательных соглашений или актов, которые добровольно исполняются сторонами или адресатами, до совершенно политических решений, вовсе не являющихся правом. Справедливыми и обоснованными выступают замечания американских правоведов А. Гузмана и Т. Мейера, полагающих, что одной из ключевых проблем, связанных с пониманием «мягкого права», служит его широта. В частности, как указывают американские ученые, «все, что похоже на право (law-like), может описываться как фрорма "мягкого права". Оно включает формально записанные документы, подписанные государствами, но по какой-то причине не удовлетворяющие требованиям соглашения; неформальный обмен обещаниями через дипломатическую корреспонденцию; голосования в международных организациях; решения международных трибуналов и многое другое. Существует так много фрорм "мягкого права", что зачастую более плодотворным будет рассматривать его как группу объектов, по крайней мере, более чем один» [10, р. 173]. Кроме того, как отмечают те же авторы, «"мягкое право" является остаточной категорией, определяемой в противовес более четким категориям, а не по его собственным признакам» [11, р. 172].

Во-вторых, «мягкое право», если оно рассматривается как самостоятельный феномен, должно обладать внутренней структурой (даже если его нельзя назвать целостным явлением). Суммативная связь различных элементов, включаемых в понятие «мягкое право», может допускаться. Однако она неустойчива, ни один из ее компонентов не приобретает при этом новых свойств, что характерно, напротив, для права и его составляющих. Неслучайно в связи с этим в правовой литературе предлагается следующая трактовка: «"Мягкое право" лучше всего понимается как континуум, или спектр, охватывающий пространство между всецело обязывающими соглашениями и чисто политическими позициями» [12]. Очевидно, что «мягкое право» не имеет устойчивой внутренней формы, синтетической связи содержащихся в нем элементов. Такая связь характерна именно для права. Каждый компонент права как целостного явления выступает частью органического целого: правовой системы, правового порядка. Например, между необязательными соглашениями или рекомендациями с одной стороны и политическими позициями с другой не существует никакой связи, кроме того что они относятся к политико-правовой сфере, выступают частью политико-правовой жизни.

В-третьих, как связано «мягкое право» с другими правовыми явлениями? Иными словами, какова его внешняя структура? Отдельные компоненты «мягкого права» вполне могут иметь связь с правом. В частности, речь идет о доктринальных актах, которые определяют основные направления политики государства в той или иной сфрере: разнообразные концепции, стратегии, доктрины, утвержденные в форме правового акта. Они не содержат обязательных правил поведения, а лишь обозначают соответствующие подходы, ключевые векторы, цели и задачи. В данном случае конкретная связь с правом позволяет отнести эти акты к правовым, а то, что они включают преимущественно рекомендации, общие подходы, формулирование целей и задач, т. е. предполагают «мягкое» или «более мягкое» воздействие на регулируемую сферу, дает возможность полностью или частично поместить их в сферу «мягко-правового» регулирования. Однако как связаны с правом политические призывы и рекомендации, политические позиции и результаты голосования? Они могут рассматриваться, например, как способ осуществления права, но это не есть само право.

Говоря в целом, внешняя связь «мягкого права» с другими правовыми явлениями носит не структурный характер, а лишь фрунциональный. Она выражается зачастую в том, что средства и инструменты так называемого «мягкого права» фрактически решают задачи, которые традиционно регулировались использованием строго правовых средств. Структурная связь прослеживается лишь фрагментарно.

«Мягкое право» решает задачи, относящиеся к политико-правовой сфере, но инструментами, которые, как правило, нельзя считать правовыми в строгом смысле слова. Значит, лишь функциональная характеристика в данном случае значима. Средства «мягкого права» являются необязательными. Именно необязательность рассматривается как некий объединяющий признак средств и механизмов «мягкого права». Однако этот признак не может трактоваться как существенный. Он неоправданно расширяет пространство для включения в понятие «мягкое право» всего чего угодно, но только не права, поскольку последнее традиционно ассоциируется с признаком общеобязательности. В результате «мягкое право» может легко трансформироваться в необъятное явление, которое просто начнет вытеснять право. «В частности, - пишут А. Гузман и Т. Мейер, - мы определяем “мягкое право” как те необязательные правила или инструменты, которые интерпретируют или делают информативным наше понимание обязательных правил или сделанных обещаний, которые в свою очередь создают ожидания относительно 
будущего поведения. Это определение сохраняет доктринальное различие между обязательными и необязательными нормами, а также обеспечивает интуитивное разграничение между квазилегальными правилами и чисто политическими правилами» [13, р. 174].

Наконец, «мягкое право» и логически, и фактически формируется как остаточный феномен по контрасту с понятием права. Пока не выработаны собственные критерии, по которым «мягкое право» может определяться как самостоятельное правовое явление, как некий вид или тип права. Функциональный подход к трактовке изучаемого понятия позволяет рассматривать его как аналитическую категорию, но только если абстрагироваться от внутренней формы «мягкого права» как правового феномена, его внутренних и внешних связей.

\section{Ссылки:}

1. Общая теория государства и права в разрешении глобализационных проблем // Теория государства и права в науке, образовании, практике : монография / Ю.Г. Арзамасов, В.М. Баранов, Н.В. Варламова и др. М., 2016. С. 405-417.

2. Дёмин А.В. Феномен «мягкого права» в регламентации трансграничного налогообложения // Государство и право. 2013. № 2. С. 63-71.

3. Велижанина М.Ю. «Мягкое право»: его сущность и роль в регулировании международных отношений : автореф. дис. ... канд. юрид. наук. М., 2007. 29 с.

4. Luhmann N. Aufsätze zur Theorie sozialer Systeme. 8. Aufl. Wiesbaden, 2009. 335 S.

5. Parsons T. Action theory and the human condition. N. Y., 1978. 464 p.

6. Luhmann N. Op. cit. S. 16

7. Ibid.

8. Керимов Д.А. Методология права. М., 2000. 560 с.

9. Там же. С. 199.

10. Guzman A., Meyer T. International Soft Law // Journal of Legal Analysis. 2010. Vol. 2, iss. 1. P. 171-225.

11. Ibid. P. 172.

12. Ibid.

13. Ibid. P. 174.

\section{References:}

Arzamasov, YuG, Baranov, VM \& Varlamova, NV (et al.) 2016, 'General theory of the state and law in solving globalization problems', Teoriya gosudarstva i prava v nauke, obrazovanii, praktike: monografiya, Moscow, pp. 405-417, (in Russian).

Demin, AV 2013, 'The phenomenon of soft law in the regulation of transboundary taxation', Gosudarstvo i pravo, no. 2 , pp. 63-71, (in Russian).

Guzman, A \& Meyer, T 2010, 'International Soft Law', Journal of Legal Analysis, vol. 2, iss. 1, pp. 171-225. https://doi.org/10.1093/jla/2.1.171.

Kerimov, DA 2000, Techniques of law, Moscow, 560 p., (in Russian).

Luhmann, N 2009, Aufsätze zur Theorie sozialer Systeme, 8. Aufl., Wiesbaden, 335 S., (in German).

Parsons, T 1978, Action theory and the human condition, New York $464 \mathrm{p}$.

Velizhanina, MYu 2007, Soft law: its essence and role in regulating international relations, PhD thesis abstract, Moscow, 29 p., (in Russian). 